\title{
DESTINO E FATALISMO EM SCHOPENHAUER
}

\author{
DESTINATION AND FATALISM IN SCHOPENHAUER
}

\author{
VILMAR DEBONA ${ }^{1}$ \\ Universidade Federal de Santa Maria (UFSM) - Brasil \\ debonavilmar@gmail.com
}

\begin{abstract}
RESUMO: Investigo a noção schopenhaueriana de destino e os dois tipos de fatalismo especificados pelo filósofo, o demonstrável e o transcendente, para, em seguida, considerá-los ante a aposta na ideia geral de uma sabedoria de vida, e vice-versa. Como seria possível admitir, por exemplo, o papel da sabedoria, referente à capacidade de o indivíduo conduzir a vida do modo mais agradável e prudente possível, no horizonte de uma filosofia que especula sobre a atuação de um destino e de um fatalismo, que tudo poderiam determinar na vida deste mesmo indivíduo? Haveria espaços concomitantes e não conflitivos para estes dois componentes no interior da filosofia schopenhaueriana? Ou se trataria de uma aporia?
\end{abstract}

PALAVRAS-CHAVE: Schopenhauer. Destino. Fatalismo. Sabedoria.

ABSTRACT: I investigate the schopenhauerian notion of destination and the two types of fatalism specified by the philosopher, the demonstrable and the transcendent, and then I considerate them in view of the general idea of a wisdom of life, and vice versa. How could admit, for example, the role of wisdom, referring to the individual's ability to conduct the life in the most pleasant and prudent way possible, in the horizon of a philosophy that speculates on the performance of a destination and of a fatalism, that could determine everything in the life of this same individual? Would there be concomitant and nonconflicting spaces for these two components within Schopenhauer's philosophy? Or would be an aporia?

KEYWORDS: Schopenhauer. Destination. Fatalism. Wisdom.

O DESTINO EMBARALHA AS CARTAS E NÓS JOGAMOS. (A. SCHOPENHAUER, APHORISMEN ZUR LEBENSWEISHEIT, P. 518)

Em $O$ mundo como vontade e representação (doravante, $O$ mundo) Schopenhauer é o pensador da metafísica imanente que toma a vontade de vida como essência do mundo e dos caracteres humanos, estes que são imutáveis, determinados, intrinsecamente desejantes e, por isso, potencializadores de dor e de sofrimento. Não há liberdade no âmbito das ações, o fundamental de cada ser - tanto na esfera moral como na intelectual e na física - é inato, e somos aquilo que somos como que por jure divino ou por theía moira. Em seus tardios Parerga

\footnotetext{
1 Professor do Departamento de Filosofia e do Programa de Pós-Graduação em Filosofia da
} Universidade Federal de Santa Maria (UFSM). 
e paralipomena, especialmente no texto dos Aforismos para a sabedoria de vida (doravante, Aforismos), o filósofo se apresenta mais como um sábio que emite conselhos sobre como lidar com aquela intransigência volitiva de cada caráter inteligível exposto pelo caráter empírico, mensagens sapienciais que frisam a via do conhecimento aprofundado de si, capaz de nos deixar decidir quais ações e ambientes renderiam menos sofrimentos pessoais, mesmo que nenhuma filosofia, religião ou educação possa mudar nossa invariável natureza. Trata-se, nos Aforismos, da aposta do pensador na elaboração e utilização de máximas de sabedoria de vida (Lebensweisheit) para o direcionamento da conduta e em vista de uma certa economia da dor. Não deixaríamos de ser egoístas e maldosos, mas o intelecto e as experiências de vida permitiriam uma incursão sobre nós, sobre os outros e sobre o mundo, legando-nos um domínio significativo de nós próprios, uma adequação de expectativas em relação ao mundo e, em certa medida, uma previsibilidade em relação à sucessão dos fatos e ações que podemos decidir. É o âmbito do que Schopenhauer denomina caráter adquirido, cômputo de toda experiência e autoconhecimento que galgamos de nós mesmos e que permitiria também sabermos o que queremos e o que podemos fazer em meio a uma miríade de desejos.

Mas, se a referida aposta na sabedoria de vida existe, como acomodá-la frente às hipóteses que não descartam a ideia de que a existência humana seja manipulada por tipos específicos de fatalismos? Suposições como esta podem ser encontradas, inclusive, na mesma obra que tem os Aforismos como um dos seus capítulos, ou seja, o Tomo I dos Parerga e paralipomena, especificamente no capítulo intitulado "Especulação transcendente sobre a aparente intencionalidade no destino dos indivíduos". Como reconhecer, então, o papel de uma sabedoria de vida, referente à capacidade de o indivíduo conduzir a vida do modo mais agradável e prudente possível, ${ }^{2}$ no horizonte de uma filosofia que especula sobre a atuação de um destino e de um fatalismo, que tudo poderiam decidir e determinar na vida deste mesmo indivíduo? Haveria espaços concomitantes e não conflitivos para esses dois componentes no interior da filosofia schopenhaueriana? Ou se trataria de uma aporia?

Schopenhauer elabora seus Aforismos de forma a semear "um suplemento nesse imenso campo já por outros trabalhado" (Idem, p. 474 [136]), o da eudemonologia. Para tanto o autor assevera que se "desvia totalmente" "do ponto de vista superior, ético-metafísico" ${ }^{3}$ de sua filosofia, motivo pelo qual toda discussão ali conduzida "baseia-se, de certo modo, numa acomodação, já que permanece presa ao ponto de vista comum, empírico" (Ibidem); acomodação que permitiria a consideração de uma "vida menos infeliz", ao invés da mera constatação da impossibilidade de uma "vida feliz". Com este intento, no capítulo V do escrito, o pensador classifica seus conselhos e exortações em "máximas gerais" e máximas que dizem respeito à nossa conduta em relação "a nós mesmos",

${ }^{2}$ Cf. A. Schopenhauer, Aphorismen zur Lebensweisheit, p. 347 [2]. Para os textos de Schopenhauer menciono a paginação no original em alemão e, entre colchetes, a correspondente paginação das traduções brasileiras (elencadas nas Referências bibliográficas). Nos casos de inexistência das últimas, a tradução é de minha autoria.

${ }^{3}$ Cf. Idem, p. $347[1-2]$. 
"aos outros" e, por último, "ao curso do mundo e do destino". Independente de qual seja a esfera em que a sabedoria de vida possa atuar, o conjunto de máximas e conselhos tem um mesmo fim, uma eudemonologia pragmática ancorada na ideia de que, pela via correta, ainda é possível decidir - se não sobre a própria felicidade, impossível de ser positivamente alcançada - sobre uma vida menos infeliz, prudente e socialmente suportável. A mais nítida intenção de uma tal eudemonologia empírica seria, em suma, a oferta de ferramentas e o uso de potenciais com vistas a "sobreviver no inferno" que é o próprio mundo. Já as características gerais do "sábio schopenhaueriano" podem ser identificadas nas próprias referidas máximas e conselhos, sendo a principal delas - destacada pelo autor em primeiro lugar, na máxima no 1 - a da prudência própria dos indivíduos que não estariam no mundo ao léu, dados à sorte, e que considerariam as adversidades desse mesmo mundo frente à busca por bem-estar pessoal. Ela é indicada justamente como a "regra suprema de toda a sabedoria de vida" e resumese na formulação de Aristóteles, da Ética a Nicômaco (VII, 12): "O prudente aspira não ao prazer, mas à ausência de dor" (Idem, p. 447 [140], grifos meus).

Porém, no mesmo capítulo dos Aforismos em que indica tais máximas e exortações, Schopenhauer retomará uma das teses fundamentais de seu pensamento: "Tudo o que acontece, do menor ao maior, acontece necessariamente" (Idem, p. 554 [242]). Voltemos, então, à nossa questão, formulando-a agora com a ordem dos fatores invertida: a razoável dificuldade se apresentaria na medida em que esta assertiva é considerada frente ao provável efeito de conselhos e máximas para uma vida sábia. Isto é, se "tudo acontece necessariamente", como se poderia continuar creditando à prudência e a outras estratégias o critério de uma vida suportável? A conquista - pela própria experiência no mundo - de uma vida sábia que evita desgraças não estaria também predeterminada pelo destino? Com efeito, não bastassem os desejos de cada indivíduo nunca satisfeitos e seus esforços malogrados, ainda pode advir - garante Schopenhauer - a zombaria do destino (Schicksal). Este ainda pode trabalhar a partir daquilo que a vontade exteriorizou em cada caráter, dando a este uma dimensão trágica, sem, no entanto, "podermos afirmar nossa dignidade de pessoas trágicas [porque], nos detalhes da vida, desempenhamos inevitavelmente o papel tolo de caracteres cômicos" (WWV I, \ 58, p. 380 [415], grifo meu). Trata-se, assim, de considerar que se estamos de posse de nosso mundo interno, de nós mesmos, ou seja, do autoconhecimento, nunca estaríamos totalmente de posse do mundo e das circunstâncias externas. E, mesmo se tivéssemos domínio sobre uma considerável parte de nosso mundo externo mediante nossa própria experiência de vida, caberia a pergunta sobre se não estaria até mesmo este domínio designado a acontecer necessariamente.

Ao retomar algumas teses fulcrais de $O$ mundo, na mencionada Especulação transcendente o filósofo diferencia duas espécies de fatalismos: o fatalismo demonstrável e o fatalismo transcendente. A primeira consideração do pensador, elaborada em termos de um esclarecimento prévio, é a de que,

embora as ideias aqui apresentadas não levem a nenhum resultado definitivo, e até mesmo possam ser consideradas meras fantasias 
metafísicas, não soube relegá-las ao esquecimento [...]. Nestas reflexões tudo é dúbio e incerto, não somente a solução, mas também o próprio problema. Dessa forma, estas páginas não prometem elucidações definitivas sobre o assunto, mas antes meras considerações sobre um conjunto de fatos muito obscuros [...], não mais que um hesitante tatear no escuro, onde se percebe que há algo, porém não se sabe exatamente onde ou o quê. (PP I, p. 243, grifo meu).

Este esclarecimento é fundamental a fim de, a princípio, não considerarmos "seriamente" estas especulações e não exigirmos delas conclusões cabais ou definitivas. Tudo o que se poderia fazer, alerta o filósofo, seria "tatear no escuro" em vista de algo indemonstrável, mas que mesmo assim poderá determinar nossa existência. A especulação é pautada na crucial tese schopenhaueriana de que "tudo acontece por necessidade absoluta, sendo esta uma verdade a ser compreendida a priori e, por conseguinte, ser considerada irrefutável” (Idem, p. 244). A impossibilidade da liberdade no plano fenomênico recebe, então, outro nome: fatalismo demonstrável.

Em vista de argumentar como este fatalismo se demonstra, o autor recorre a sonhos proféticos, oráculos, antecipações do futuro por videntes ${ }^{4}$ e, dentre as histórias ou tragédias dos antigos, limita-se a citar o Édipo-Rei e a história de Creso e Adastro, esta narrada por Heródoto. Tratar-se-iam de chocantes confirmações empíricas de algo que nem mesmo é afetado por deliberações racionais e não advém da relação entre caráter e motivos; prognósticos cujas tentativas de evitálos acabam por promovê-los. Não restariam dúvidas, pois, de que, por mais que o transcurso das coisas se apresente como fundamentalmente casual, "no fundo não

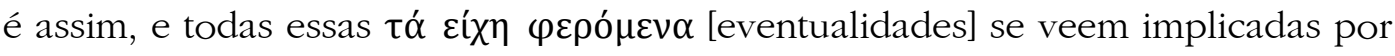
uma necessidade, é́ $\mu \alpha \rho \mu \varepsilon ́ v \eta$ [destino] [...]” (p. 125-166). Para o caso deste fatalismo demonstrável, pressupõe-se, então, um "juízo estritamente teórico" que se desenlaça empiricamente, muitas vezes de forma repentina, anulando toda e qualquer atuação do indivíduo ou então o mínimo que seja de um "espaço de manobra" de sua parte.

Mas o mais enfático e incisivo fatalismo, de ordem superior, seria o transcendente. Apesar de aquela primeira forma de fatalismo [o demonstrável] já encerrar grandes dificuldades diante de planejamentos e da conquista de uma "vida sábia”, é na ocasião em que expõe suas reflexões sobre o fatalismo transcendente

\footnotetext{
${ }^{4}$ Schopenhauer cita em nota um caso judicial publicado no Times de 2 de dezembro de 1852: "Em Newent, Glocestershire, realizou-se uma investigação judicial, instruída pelo juiz Mr. Lovegrove, sobre o cadáver de um homem chamado Mark Lane que fora encontrado afogado. O irmão da vítima declarou que, ao ser informado do desaparecimento de seu irmão, replicou de imediato: 'Deve ter se afogado, pois esta mesma noite sonhei que, submerso eu mesmo n'água, fazia esforços para tirá-lo fora'. Na noite seguinte sonhou novamente que seu irmão tinha morrido afogado próximo a Oxenhall, onde viu uma truta na água. No momento ficou persuadido de que seu irmão deveria encontrar-se lá e, efetivamente, o cadáver foi encontrado naquele lugar". Frente ao relato, o pensador escreve: "Assim, pois, algo tão fortuito como o salto de uma truta foi previsto muitas horas antes com uma precisão cronométrica!” (idem, p. 245). Para uma interessante e rica investigação desses e outros fenômenos, e de sua importância para a metafísica schopenhaueriana, cf. SILVA, 2017, esp. cap. 5.
} 
que Schopenhauer questiona diretamente a relação entre aquelas duas esferas, pois este último fatalismo "vai-se decantando paulatinamente a partir das experiências do próprio transcurso vital” (Idem, p. 247). Esta concepção inspira-se em presságios e em sensações de que tudo o que nos acontece ou o que conseguimos realizar e conquistar durante a vida já estaria "previamente decidido"; tratar-se-ia de algo que envolveria firmemente o indivíduo temporária ou permanentemente, fazendo-o perceber que "a necessidade de tudo o que acontece não é cega [...]" (Idem, p. 246, grifo do autor). Admitida esta hipótese, despojar-se-ia o indivíduo de suas ferramentas de sabedoria, não obstante suas malogradas tentativas de ser prudente ou menos infeliz, confirmando-o como fantoche da vontade cósmica. Seria sempre esta última que, ao final, levantaria o mesmo troféu do qual, a duras penas, tal indivíduo chegou a cogitar ser merecedor. Ou seja, para tudo seria uma questão de tempo: cedo ou tarde o indivíduo perderia. Inocente em relação ao poderio deste fatalismo, todos os seus esforços e todas as suas tentativas seriam vãos. E, mais ainda: até mesmo a concatenação dos acontecimentos da vida de uma pessoa, aquela espécie de "resolução definitiva" ou "esboço de si mesmo" referida pelo filósofo em termos de uma atmosfera favorável a ser reconhecida por cada indivíduo, a própria conquista do caráter adquirido, também já estaria prédeterminada; e, por mais que as formas de se atuar no mundo tenham sido variadas, ao final se entenderia que toda esta diversidade de formas também já estaria decidida desde sempre. Nesse sentido, Schopenhauer cita o tradutor de Lucrécio para a língua alemã, Karl Knebel: ${ }^{5}$

Ao aguçar suas observações, alguém pode descobrir que na vida da maior parte dos homens foi traçada uma espécie de plano pela própria natureza ou então pelas circunstâncias que os guiam. As condições de suas vidas podem ser versáteis e inconstantes, mas ao final se mostram numa totalidade a partir da qual se pode apreciar certa concordância; a mão de um destino determinado, por mais secretamente que atue, deixa-se ver com precisão [...]. (KNEBEL, 1840, p. 452 apud PP I, p. 248).

Esse processo de atuação possível do destino jamais perderia o solo da metafísica imanente da vontade. Como formula Atzert, o lugar de onde esses "processos" são geridos são os "[próprios] indivíduos, mesmo que [um lugar] não acessível à consciência normal, o que, por isso, será experimentado como sendo dirigido por um "poder estranho" (ATZERT, 2005 p. 187). Em todo caso, se considerarmos mesmo que hipoteticamente a atuação desse fatalismo transcendente, então teríamos de admitir que, mesmo aqueles indivíduos que conseguem - não obstante a imutabilidade e o inflexível corolário de seu caráter inato - adquirir sabedoria, compreenderiam também que até mesmo isso já estaria "previamente traçado". Nesse caso, a constatação de um ancião prudente de que, após décadas de fadiga, alcançou um ambiente propício, consequência de seus esforços, não passaria de "doce ilusão", válida apenas enquanto não entendesse

\footnotetext{
${ }^{5}$ Karl Ludwig Knebel (1744-1834) foi um poeta e ficou conhecido em Weimar como o preceptor do filho da duquesa Amélia.
} 
que todos os acontecimentos e decisões guardam uma estreita ligação não decidida por ele.

A dificuldade aqui apresentada entre fatalismo, destino e possíveis êxitos da sabedoria de vida poderia ser especialmente iluminada se considerada sob a presença ou não daquele "desvio proposital da metafísica" efetuado por Schopenhauer no início dos Aforismos para tratar da sabedoria de vida. Ou seja, teríamos de considerar em que momentos o pensador argumenta suas teses do ponto de vista metafísico (sobretudo, em $O$ mundo, mas também na referida Especulação transcendente), atribuindo a tais teses a tarefa da decifração do enigma do mundo, e em que momentos o faz de um ponto de vista empírico ou mesmo prático-pragmático (sobretudo, nos Aforismos). Tão logo esta questão metodológico-contextual passe a ser considerada como determinante, teríamos para o nosso problema ao menos dois argumentos ou elementos cruciais a partir dos quais poderíamos, se não resolver a dificuldade, ao menos lançar alguma luz sobre a suposta aporia.

O primeiro argumento diz respeito à possibilidade de atuação do fatalismo transcendente: o próprio filósofo afirma não pretender ultrapassar a esfera da especulação. O título de seu escrito já indica que se trata de uma "especulação transcendente" e, embora se tenha indícios - ou mesmo argumentos - para defender essa espécie de fatalismo, é preciso limitar-se a uma possibilidade especulativa. Em outros termos, o primeiro elemento que pode auxiliar no enfrentamento da dificuldade aqui tratada é aquele que considera a efetividade desse fatalismo de ordem superior apenas como provável. Trata-se justamente do sentido do "esclarecimento prévio" formulado por Schopenhauer na abertura desse seu escrito. Se não fosse apenas probabilístico e restrito a especulações, também não seria necessário um mero "tatear no escuro" e, mais ainda, saber-se-ia objetivamente do que se trataria e onde residiria o problema.

O segundo e mais importante argumento pode ser formulado da seguinte forma: as teses que supostamente sustentam tanto o fatalismo demonstrável quanto o fatalismo transcendente fazem parte do intento schopenhaueriano de "decifrar o enigma do mundo", ou seja, pertencem ao âmbito metafísico dessa filosofia. É por isso que, no mencionado ensaio sobre o fatalismo, o pensador afirma: "O que conjecturamos aqui como atuante não seria a natureza, mas sim uma instância metafísica situada além da natureza, a qual existe de forma total e indivisa em cada indivíduo [...]" (PP I, p. 250). Desse modo, seria ainda mais fundamental considerar como Schopenhauer, principalmente nesta "especulação transcendente", enfatiza a ideia de que não existe um grande esclarecimento sobre questões relacionadas ao tema do fatalismo e do destino. Tratar-se-ia de uma espécie de limite para a "decifração do enigma do mundo", cuja insistência em se compreender seus fundamentos conduziria de volta ao plano da objetivação da vontade, esta uma essência sem fundamento, pormenorizadamente considerada em $O$ mundo. Além disso, lançar-se à tentativa de encontrar um fundamento para o fatalismo significaria, conforme explica o próprio pensador, ter de responder previamente a todas estas perguntas: "pode ocorrer um desacordo total entre o caráter e o destino de uma pessoa? Ou significa que, quanto ao principal, cada destino conecta-se a 
seu correspondente caráter? Ou haveria ainda, em última instância, uma necessidade secreta e inconcebível, comparável ao autor de um drama, que sempre acaba unindo um ao outro?" (Idem, p. 250-251). Isto é, a tentativa de fornecer respostas a estes questionamentos corresponderia a ignorar a constatação de que nem tudo pode ser tratado unicamente sob o viés metafísico. Há certas explicações que somente podem ser dadas a posteriori: a impossibilidade de uma explicação para o caso de um total desacordo entre o caráter e o destino de alguém não eliminaria a possibilidade de uma resposta quando, por exemplo, "lançamos um olhar retrospectivo sobre as etapas de nossa vida, passando em revista sobretudo nossos passos desafortunados e suas consequências", mesmo que a resposta para tanto seja a de que tudo fora obra de uma "força estranha".

No entanto, este "olhar retrospectivo" pode ser tomado a fim da obtenção de possíveis "respostas" às questões lançadas pelo próprio Schopenhauer de um outro ponto de vista, o empírico-pragmático, que permitiria uma certa tentativa de dirimir as dificuldades entre as esferas do destino e da sabedoria de vida. Para tanto, é preciso considerar a análise que não atribui o reconhecimento do indivíduo - ou a exposição de seu caráter a partir de um olhar a posteriori de sua trajetória no mundo - meramente ao destino ou a uma "força incontrolável" e inacessível. Principalmente no texto dos Aforismos, a questão do destino, por exemplo, é tratada de uma outra forma. Se na Especulação transcendente o tema é abordado sob o viés metafísico, nos Aforismos esse mesmo tema se insere em uma perspectiva empírico-pragmática. A mesma diferença se mostra quando se compara a abordagem do tema em $O$ mundo com aquela dos Aforismos. No plano metafísico da obra magna, no qual se insere o tratamento da vontade como grundlos, encontra-se o pressuposto de um mundo e de um indivíduo determinados pelo efeito de uma vontade cega e incessante. Mas não precisaríamos de muito esforço para percebermos como a abordagem schopenhaueriana desse mesmo indivíduo muda significativamente quando formulada no plano da sabedoria de vida.

Desempenhar inevitavelmente o papel tolo de caracteres cômicos, por exemplo, pode valer como proposição pertinente no plano metafísico da determinação da vontade, mas não necessariamente no plano eudemonológico. Se em $O$ mundo Schopenhauer toma como certa a influência da zombaria do destino, nos Aforismos, especificamente na ocasião em que indica máximas, o pensador está certo de que aquilo que comumente chamamos destino muitas vezes não passa de nossos próprios atos tolos, porque não se deve "perder a coragem e pensar que é impossível dirigir (leiten) nossa conduta na vida mundana em conformidade com regras e máximas abstratas [...]" (A, p. 533 [215-216]). A questão é claramente deslocada, com isso, de uma abordagem metafísica para uma dimensão pragmática. Não obstante um ser determinado e, talvez, até zombado pelo destino, ainda haveria a possibilidade de os atos não serem demasiados tolos e, nesse sentido, totalmente determinados.

Poderíamos considerar essa possibilidade quando observamos, por exemplo, que nos Aforismos Schopenhauer afirma: "O curso da nossa vida não é certamente nossa obra exclusiva, mas o produto de dois fatores, a saber, a série 
dos acontecimentos e das nossas decisões. Séries que sempre interagem e se modificam reciprocamente" (Idem, p. 548 [234], grifos meus). Estaríamos, assim, retomando a aposta na conquista da sabedoria de vida mediante as noções de autoconhecimento e de prudência. Essa conquista seria resultado de exercícios, estratégias e decisões e, por conseguinte, a noção de destino é considerada de forma independente da nossa atuação no mundo. Isso fica mais claro quando percebemos que Schopenhauer, ao reservar o último tópico das Parêneses e Máximas, nos Aforismos, exclusivamente para o tratamento da Nossa conduta em relação ao mundo e ao destino, trata este último como algo não necessariamente atuante no curso de vida do indivíduo, relativizando assim sua "força fatalista". Trata-se, agora, da atuação de "dois fatores"; e o que se entende por destino, nesse sentido, estaria mais próximo do que se chama "azar" ou "sorte", o que não necessariamente anula o êxito de exercícios e de aprendizados adquiridos. A consideração de Schopenhauer quanto a estes últimos é a de que, tal como o corpo é algo físico e necessita de exercícios para ser saudável, também o intelecto é acessível ao hábito. Tudo na vida necessita de movimento, pois "até as árvores, para prosperar, precisam ser agitadas pelo vento" (Idem, p. 385 [19]), ainda que tais movimentos não devam ser forçados. Assim, se ao acentuar o elevado valor da saúde como elemento importante para a felicidade, o filósofo recomenda a proteção dos olhos em relação à luz muito intensa, dos ouvidos em relação a ruídos demasiado fortes, assim também "o cérebro não deve ser submetido a trabalho forçado, incessante ou extemporâneo” (Idem, p. 517 [196]). O pensar, aqui, significa tão somente a função orgânica do cérebro. Este, analogamente a qualquer outra atividade orgânica, será mais ativo, renderá mais ou não, a depender de seu esforço e de seu repouso. Estaria ao nosso alcance, então, aperfeiçoar funções e habilidades que lhe são próprias em vista de um "melhoramento" de sua atuação na vida.

O assunto também é objeto da Máxima 17 dos Aforismos, na qual lemos que "também nossa vida interior e intelectual requer ocupação contínua" (Idem, p. 513 [190]). Em verdade, reside aqui o propósito do "papel do intelecto" que o filósofo enfatiza logo no início dos Aforismos, ocasião em que, após relembrar de nossa subjetividade enquanto dada por jure divino, fixa e inalterável, repete (de forma reelaborada) o que já havia cunhado nos Adversaria, de 1829: "A única coisa que podemos fazer é empregar a personalidade e [...] alcançar um tipo de formação que lhe seja conveniente" (Idem, p. 379 [11]). Ora, somente poderíamos empregar nossa personalidade se, antes, a reconhecêssemos como tal, justamente na medida em que estamos de posse do caráter adquirido. À maneira de exercícios físicos, pois, tratar-se-ia de estimular e aperfeiçoar determinados aspectos do intelecto a fim de se obter, quiçá, uma vida menos afetada pelo destino. Não relegaríamos, dessa forma, todas as decisões ao acaso ou aos acontecimentos, mas participaríamos ativamente mediante "sugestionamentos" do intelecto.

Estas recomendações - quanto ao exercício do cérebro, por exemplo - são possíveis no pensamento schopenhaueriano porque a noção de destino, no âmbito dos Aforismos, é tratada "independentemente" de nossas decisões, ao contrário da abordagem que frisei anteriormente, da esfera metafísica ou transcendente, tal 
como elaborada no escrito sobre o fatalismo. Neste ínterim, é importante notar que quando se refere ao termo destino, no ensaio da Especulação transcendente, o pensador usa o termo grego cí $\mu \alpha \rho \mu \varepsilon ́ v \eta$ (no sentido de Notwendigkeit). Já quando se refere ao mesmo termo nos Aforismos, emprega o vocábulo tuxך, complementando a sua intenção de usá-lo, desta feita, conforme a expressão latina secunda aut adversa fortuna (sorte favorável ou adversa, que em alemão também é Schicksal). ${ }^{6}$ Esta simples variação terminológica não permitiria afirmar que, doravante, estaríamos "livres" em relação ao destino, mas permitiria considerar que o referido destino pode não representar mais que uma "falta de sorte". O poder maior ainda estaria com o destino enquanto "sorte" porque diante dele, mesmo no âmbito dos Aforismos, Schopenhauer afirma ser os "nossos esforços e os nossos empenhos de muito pouca serventia" (Idem, p. 547 [233]). No entanto, isso não aduz mais àquele fatalismo demonstrável explanado anteriormente.

Mas não haveria nenhuma forma de exercício ou estratégia a nosso alcance com a qual pudéssemos outorgar mais importância à "serventia" de nossos esforços? A princípio, o simples fato de haver "pouca serventia" de tais esforços já significaria que não necessariamente estaríamos total e plenamente determinados. Não obstante ser a sorte o poder mais forte, ela não é a única. Aliás, assim afirma o pensador: "Um escritor antigo disse com bastante pertinência que há três poderes

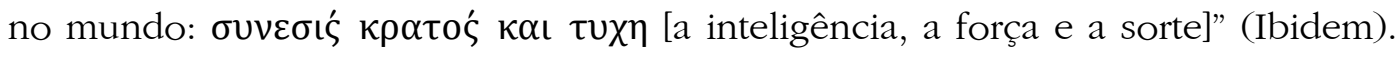
De acordo com isso, ainda estariam à nossa disposição a força e a inteligência, sendo esta última a mais determinante. Sendo assim, haveria, sim, um "exercício estratégico" possível frente à sorte (destino): saber empregar, no momento adequado, os atributos da inteligência, estes também "reforçados" previamente por exercícios e estímulos. Tratar-se-ia, portanto, de articular exercícios, mesmo diante daquilo que não está ao nosso alcance decidir.

Podemos ter presente a parcela da importância de exercícios ou estratégias quando consideramos, por exemplo, que o caminho de nossa vida é comparável ao curso de um navio:

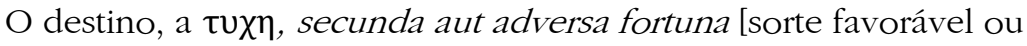
adversal, desempenha o papel do vento que nos impele rapidamente para adiante, ou para trás, sendo os nossos esforços e os nossos empenhos de muito pouca serventia. Estes desempenham o papel dos remos: quando, depois de muitas horas de trabalho, fizeram-nos avançar no percurso, uma súbita rajada de vento faz-nos regredir o mesmo tanto. Ao contrário, se este último é favorável, avançamos de tal modo que nem precisamos dos remos (Ibidem).

Por um lado, pois, o poder mais influente seria o da sorte. Não há planejamento ou estratégia que represente ameaça ao destino quando este é considerado enquanto sorte ou azar. Por outro lado, porém, sublinho a ideia do quão determinante e forte seria poder estar em uma atmosfera favorável para, somente a partir disso, poder saber se os "remos" são determinantes ou se estamos

${ }^{6}$ Cf. Idem, p. 547 [233]. 
à mercê dos "ventos". Poderíamos ponderar quais seriam as condições mais favoráveis para se poder "navegar" sem os obstáculos dos "ventos". Caso pudéssemos vislumbrar a ausência de ventos ou a presença de "ventos brandos", então haveria espaço para nossos esforços, a serventia dos "remos" não seria pouca e poderia até nos render grandes vantagens. Ademais, o próprio fato de o destino assumir o caráter de imprevisibilidade nos forneceria motivos para não ignorarmos um possível êxito dos "remos". Estar de posse destes últimos significaria possuir ferramentas mediante as quais os exercícios de sabedoria de vida seriam possíveis em "horas de calmarias", podendo estas ser até mais longas que as "horas de turbulências".

Nesse mesmo sentido, temos outra alegoria: "Na vida, as coisas acontecem como no jogo de xadrez: esboçamos um plano que, todavia, fica condicionado à vontade do adversário, no jogo, e à do destino, na vida" (Idem, p. 518 [235]). É como se houvesse duas forças - os acontecimentos e as nossas intenções - agindo em direções opostas, sendo o resultado desta ação o próprio curso de vida de cada indivíduo. Mas a questão nevrálgica pode ser melhor explanada a partir da máxima "o destino embaralha as cartas, e nós jogamos" (Ibidem). Assim, se considerarmos um jogo de cartas do mesmo modo como consideramos um jogo de xadrez, e se as cartas não são favoráveis ao jogador, caberia a este último encontrar artifícios e estratégias de acordo com suas circunstâncias reais, ou seja, a partir do que a sorte lhe ofereceu. A depender das condições do jogo, poder-se-á articular diferentes estratégias, muito embora estas sempre fiquem à mercê ou condicionadas às decisões do adversário. O importante é "jogar", em vista do que haveria algumas estratégias possíveis: ficar atento (ou prudente) em relação aos lances adversários; planejar a jogada mais conveniente ou adequada diante de cada nova situação; evitar jogadas inconvenientes ou menos proveitosas etc.

Por fim, como última máxima do Capítulo V dos Aforismos, temos ainda outro argumento para uma possível resposta eudemonológica sobre o papel de nossos esforços frente ao fatalismo ou à sorte: "[...] depois da inteligência, a coragem é uma qualidade bastante essencial para a nossa felicidade" (Idem, p. 555 [224]). Se, por um lado, não podemos escolher as parcelas de nossa inteligência e de nossa coragem, pois já as herdamos, por outro lado, "mediante firme propósito e exercício, podemos incrementar o que já possuímos" (Ibidem). E é justamente nesta última "exortação" aforismática do capítulo das Máximas, que verificamos um anelo de esperança: "[...] enquanto houver a possibilidade de um resultado favorável, não pensemos em fraquejar, mas em resistir; do mesmo modo, não devemos nos desesperar em relação ao clima enquanto houver um ponto azul no céu" (Idem, p. 556 [244-245]). E não poderia ser em outra ocasião que o pensador citasse o sábio estoico Horácio: "Si fractus illabatur orbis, impavidum ferient ruinae, se o mundo desmoronasse, as ruínas o atingiriam sem apavorá-lo" (Idem, p. 556 [245]). Quando sucede o contrário, tem-se, segundo o filósofo, uma "alma covarde" cuja primeira decisão frente a "nuvens negras e condensadas" seria abater-se e pôr- 
se a lamentar. Do lado oposto estaria o indivíduo que não se abateria e que corajosamente lutaria. ${ }^{7}$

É possível, portanto, não descartarmos a "zombaria do destino" sem que deixemos de apostar no conhecimento de si, na prudência e na coragem. Mesmo que a princípio soe algo aporético, a filosofia schopenhaueriana consegue abrigar os dois elementos em questão - o do fatalismo, por um lado, e o da sabedoria, por outro - sem que um elimine o outro. Diríamos que os mencionados fatalismos, com suas forças implacáveis, participam da metafísica da vontade de $O$ mundo enquanto fenômenos dela decorrentes. Por sua vez, o registro da sabedoria de vida em chave não-metafísica leva em conta o poderio transcendente e demonstrável desses fenômenos ou do destino, o que percebemos a partir do uso feito pelo filósofo de metáforas como a do navio ou a da navegação e a do jogo de xadrez. Com estratégias de jogo bem articuladas e com sorte, talvez não sucumbamos tão cedo. E, assim, poderíamos ainda pronunciar, como se diz em várias línguas e Schopenhauer soube registrar: degere vitam, vita defungi (levar a vida, vencer a vida), si scampa così (assim vai-se vivendo), man muss suchen, durchzukommen (tem-se de tentar sobreviver) ou, então, er wird schon durch die Welt kommen (ele há de sobreviver por esse mundo afora). ${ }^{8}$

\section{REFERÊNCIAS BIBLIOGRÁFICAS}

ATZERT, Stephan. Zwei Aufsätze über Leben und Tod: Sigmund Freuds "Jenseits des Lustprinzips" und Arthur Schopenhauers "Transscendente Spekulation über die anscheinende Absichtlichkeit im Schicksal des Einzelnen". SchopenhauerJahrbuch, Würzburg, v. 86, p. 179-194, 2005.

KNEBEL, Karl Ludwig von. Literarischer Nachlass und Briefwechsel. Hrsg. von K. A. Varnhagen von Ense und Th. Mundt. Leipzig: Gebrüder Reichenbach, 1840.

SCHOPENHAUER, Arthur. Sämtliche Werke. Hrsg. von Paul Deussen. 16 Bd. München: Piper Verlag, 1911-1941 (Schopenhauer im Kontext III: Werke, Vorlesungen, Nachlass und Briefwechsel auf CD-ROM - Release jan. 2008).

Aphorismen zur Lebensweisheit. In: SCHOPENHAUER, Arthur. Sämtliche Werke. Hrsg. von Paul Deussen. Bd IV. München: Piper Verlag, 1911-1941.

Die Welt als Wille und Vorstellung, I. In: SCHOPENHAUER, Arthur. Sämtliche Werke. Hrsg. von Paul Deussen. Bd. I. München: Piper Verlag, 19111941.

\footnotetext{
${ }^{7}$ Ao destacar a necessidade da coragem frente à fatalidade e ao destino, Schopenhauer recorre a Schiller e a Voltaire. Do primeiro, cita o início da poesia "Die Schlacht" "A batalha"), na qual se lê que neste mundo die Würfel eisern fallen (os dados caem implacáveis). Do segundo, menciona e elogia a seguinte passagem: On ne réussit dans ce monde, qu’à la pointe de l'épée, et on meurt les armes à la main (Só triunfamos neste mundo com a ponta da espada, e morremos com as armas na mão) (Cf. Idem, p. 555 [244]).

${ }^{8}$ Cf. Idem, p. 475 [141].
} 
Parerga und Paralipomena, I. In: SCHOPENHAUER, Arthur. Sämtliche Werke. Hrsg. von Paul Deussen. Bd IV. München: Piper Verlag, 1911-1941.

O mundo como vontade e como representação. Tomo I. Trad. Jair Barboza. São Paulo: Unesp, 2005.

Aforismos para a sabedoria de vida. Trad. Jair Barboza. São Paulo: Martins Fontes, 2006.

SILVA, Luan Corrêa. Metafísica prática em Schopenhauer. Tese (Doutorado em Filosofia). Universidade Federal de Santa Catarina, Centro de Filosofia e Ciências Humanas. Programa de Pós-Graduação em Filosofia. Florianópolis, Santa Catarina, 2017, 177 p.

Recebido em: 23-07-2018

Aceito para publicação em: 02-11-18 